\title{
RANCANG BANGUN SISTEM INFORMASI MANAJEMEN ADMINISTRASI MAPLOEG
}

\author{
Syarip Hidayat ${ }^{1}$, Nazwirman ${ }^{2}$ \\ ${ }^{I}$ Teknik Informatika Universitas Islam Syekh-Yusuf Tangerang \\ ${ }^{2}$ Program Magister Manajemen Universitas YARSI, Jakarta \\ ${ }^{1}$ syarip_yusup@gmail.com \\ ${ }^{2}$ nazwir10@gmail.com
}

\begin{abstract}
Abstrak- Penelitian bertujuan memudahkan pegawai Bank Tabungan Negara (BTN) Cabang Karawaci dalam mencari bukti dalam arsip maploeg yang dibutuhkan. Sistem register Maploeg di BTN masih bersifat konvensional yang tidak tersusun dengan baik sehingga rentan kehilangan arsip terutama sulit dalam pencarian sehingga memerlukan waktu yang lama. Sistem ini dibuat agar dapat mengontrol alur register Maploeg baik agar lebih efisien dan memudahkan pegawai saat membutuhkannya. Perancangan Sistem menggunakan Use Case dan Sequence Diagram. Perangkat Lunak dengan PHP dan Mysql
\end{abstract}

Kata Kunci- Bank Tabungan Negara, Administrasi, Register, Maploeg, Java.

\section{PENDAHULUAN}

Mengembangkan sistem perbankan yang sehat dan kuat merupakan syarat penting bagi suatu negara dalam mendukung upaya pembangunan nasional secara berkesinambungan (Hermansyah, 2014). Kondisi yang demikian disebabkan industri perbankan memiliki peran yang sangat strategis dalam perekonomian, karena sebagai lembaga intermediasi dan penunjang sistem pembayaran (Hermansyah, 2014). Eksistensi perbankan dalam suatu negara ikut berkontribusi dalam upaya meningkatkan perwujudan kesejahteraan rakyat. Tidak ada suatu negara yang iklim perekonomiannya dapat hidup dan berkembang pesat tanpa perantaraan perbankan. Bahkan dalam sistem ekonomi modern, perbankan sebagai jantung yang dari perekonomian (Udin, 2008). Kondisi perbankan yang sehat dan efisien menjadikan perekonomian nasional akan mampu tumbuh dengan baik. Dalam undang-undang Nomor 10 tahun 1998 tentang perbankan, Bank disebutkan sebagai badan usaha yang menghimpun dana dari masyarakat dalam bentuk simpanan dan menyalurkan kepada masyarakat dalam bentuk kredit dan bentuk-bentuk lainnya dalam rangka meningkatkan taraf hidup masyarakat.

Bank Tabungan Negara (BTN) merupakan salah satu Bank yang dimiliki oleh Badan Usaha Milik Negara yang berbentuk perseroan terbatas dan bergerak dibidang jasa keuangan serta memberikan fasilitas kredit penyediaan perumahan. Sebagai lembaga milik pemerintah BTN memiliki cabang di hampir seluruh wilayah di Indonesia dan salah satunya adalah Cabang Karawaci yang melayani berbagai transaksi keuangan meliputi menghimpun dana dalam bentuk tabungan, giro, deposito, transaksi kiriman uang, dan juga kredit perumahan. Dari berbagai transaksi yang ada di Bank Tabungan Negara cabang Karawaci ada beberapa transaksi seperti menghimpun dana dalam bentuk tabungan, giro, deposito, transaksi kiriman uang, ini harus di jadikan sebuah laporan yang disebut maploeg.

Berdasarkan hasil pengamatan yang peneliti lakukan selama 4 (empat) bulan dari November 2016 sampai Februari 2017 ada 154 atau 92 persen maploeg teregister, dan 113 atau 8 persen belum teregister. Artinya masih dimungkinkan terjadinya hambatan. Mengingat perannya bagitu strategis maka penelitian membangun sistem untuk mengatai masalah tersebut. Tujuannya adalah petugas Bank tidak lagi kesulitan dalam mencari bukti dasar yang dibutuhkan.

Penelitian ini bermaksud untuk merancang sistem informasi maploek guna membantu mempercepat proses pengarsipan di BTN Cabang Karawaci. Proses berjalan meliputi: pertama Prosedur awal, Nasabah datang ke Bank BTN, Security menyambut nasabah, memberikan nomor antrian dan slip, dan Nasabah mengisi slip menabung atau pembayaran. Kedua Prosedur Transaksi, Nasabah datang ke Teller untuk transaksi. Teller menerima slip dari nasabah dan memroses transaksi sesuai permintaan nasabah, kemudian Teller mencetak 2 (dua) rangkap slip hasil transaksi, (rangkap 1 (satu) untuk nasabah rangkap 2 (dua) untuk arsip. Ketiga, Prosedur Maploeg, Teller 
merekapitulasi dari slip rangkap 2 (dua) hasil transaksi harian menjadi Maploeg. Teller enyerahkan Maploeg kepada petugas setiap hari (melakukan registrasi maploeg manual) (Gambar 1)

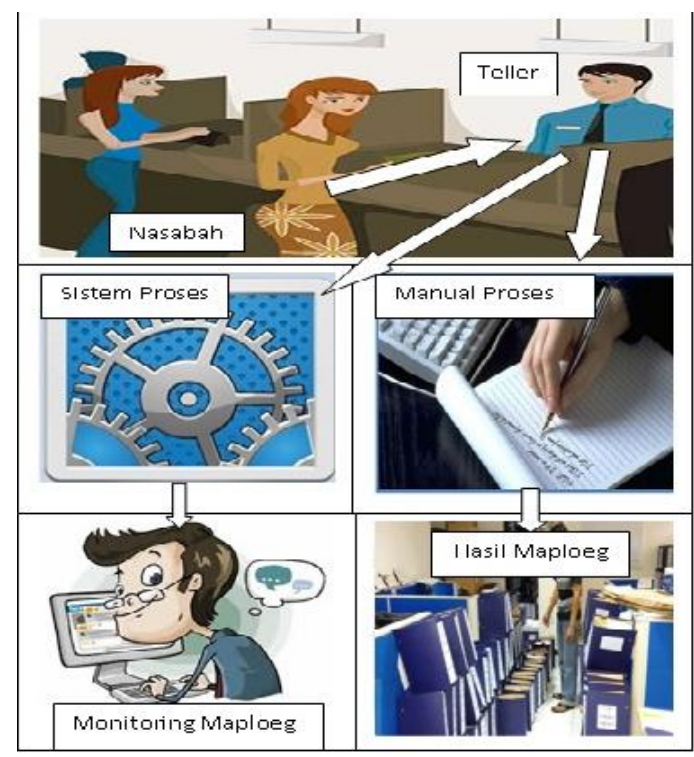

Gambar 1. Mapping Sistem

Rancangan sistem menggunakan Unified Modeling Language (UML) yang merupakan spesifikasi standar untuk mendokumentasikan, menspesifikasikan, dan membangun sistem perangkat lunak. Data base dirancang menggunakan PHP dan Mysql. PHP merupakan bahasa pemrograman yang dapat digunakan untuk membuat skrip yang lebih interaktif. Skrip ini kemudian diolah dalam web server yang hasilnya dapat dilihat dalam bentuk HTML (Mahdiana, 2011; Mustikowati, 2013; Jayanti, Dwi \& Siska Iriani, 2014). PHP memungkinkan situs yang lebih interaktif dan lebih mudah untuk dioperasikan. MySQL merupakan bahasa pemrograman database terbuka. Dimana memungkinkan untuk bisa membuat, merubah, dan mengakses beberapa database sekaligus dalam server (https://id.wikihow.com, diunduh 6 Maret 2018).

\section{Kajian Teori}

\section{Sistem Informasi}

Sistem Informasi adalah suatu gambaran sistem otomatis (yang dapat disebut sebagai Sistem Informasi terkomputerisasi), baik manual, yang meliputi orang, mesin atau metode terorganisasi untuk mengumpulkan, memproses, mengirim dan menyebarluaskan data yang mewakili informasi bagi pengguna (David, 2015). Whitten et al., (2004) informasi merupakan pengaturan orang, data, proses, dan teknologi informasi yang berinteraksi untuk mengumpulkan, memproses, menyimpan dan menyediakan sebagai output informasi yang dibutuhkan untuk mendukung suatu organisasi," yang menunjukkan bahwa sistem informasi adalah pengaturan kelompok, data, proses dan teknologi yang bertindak bersama untuk mengakumulasi, memproses, menyimpan dan menyediakan output informasi yang diperlukan untuk meningkatkan dan mempercepat proses pengambilan keputusan. Dalam sistem informasi Bank, selalu ada potensi krisis yang membuat bank menanggung ketidakcukupan; dengan demikian, sistem informasi lanjutan yang didukung oleh kontrol mekanisme yang unggul diperlukan untuk memastikan bahwa suatu sistem informasi telah mencapai proses yang diperlukan. Jika informasi relevan yang diperlukan dalam proses pengambilan keputusan atau perencanaan organisasi tidak tersedia pada waktu yang tepat, maka ada perubahan yang baik untuk menjadi perencanaan organisasi yang buruk, pengambilan keputusan yang tidak tepat, prioritas kebutuhan yang buruk, dan pemrograman yang rusak atau penjadwalan kegiatan (Adebayo, 2007).

Sistem informasi komputer adalah sistem yang merupakan cabang Ilmu yang terdiri dari orangorang dan komputer yang memproses atau menafsirkan informasi (D'Atri et al., 2008; Leonard \& Joseph, 2008).

\section{Administrasi Maploeg}

Ada dua pengertian administrasi, yaitu administrasi dalam arti sempit dan administrasi dalam arti luas. Dalam arti sempit adalah kegiatan penyusunan dan pencatatan data dan informasi secara sistematis dengan tujuan untuk menyediakan keterangan serta memudahkan memperolehnya kembali secara keseluruhan dan dalam satu hubungan satu sama lain. Sedangakan dalam arti luas adalah kegiatan kerja sama yang dilakukan sekelompok orang berdasarkan pembagian kerja sebagaimana ditentukan dalam struktur dengan mendayagunakan sumber daya untuk mencapai tujuan secara efektif dan efisien. Jadi, pengertian administrasi dalam arti luas memiliki unsur-unsur sekelompok orang, kerja sama, pembagian tugas secara terstruktur, kegiatan yang runtut dalam proses, tujuan yang akan dicapai, dan pemanfaatan berbagai sumber (Haryadi, 2011). Jadi administrasi adalah seluruh kegiatan dari pengaturan dan pengurusan kelompok orang yang memiliki diferesiansi pekerjaan untuk mencapai suatu tujuan bersama. Sedangkan Maploeg adalah berbagai macam dokumen transaksi dan dokumen lainnya selama sehari berjalan yang disusun secara rapi dan teratur. Maploeg ini akan dikirim ke Kantor Cabang untuk diarsip dan diolah.

\section{METODE PENELITIAN}

Metode penelitian menggunakan metode deskriptif, yang menyajikan gambaran mengenai 
suatu fenomena dengan mendeskripsikan pemecahan masalah yang diselidiki dengan gambaran keadaan subjek atau objek yang berkenaan dengan unit pada saat sekarang.

Sumber data diperlukan adalah data primer dan data sekunder. Data primer dengan observasi langsung ke objek yang diteliti dan wawancara ke beberapa pegawai. Data sekunder yaitu dengan studi literatur yang berasal dari jurnal, buku dan internet.

\section{HASIL DAN PEMBAHASAN}



Gambar 2. Use Case Diagram meliputi Transaksi. Proses transaksi. Laporan Maploeg, dan 6 (enam) Message spesifikasi dari komunikasi antar objek yang memuat informasiinformasi tentang aktifitas yang terjadi.

Hasil Tampilan Program yang ditampilkan yaitu (Gambar 4):

\section{Bank 周 BTN

 \\ Gambar 4. Tampilan Login}

Setelah admin login setelah memasukan username dan password dengan benar, maka munculah tampilan (Gambar 5) seperti ini:
Berdasarkan Gambar 2 Use Case Diagram terdapat 1 (satu) sistem yang mencakup seluruh kegiatan sistem maploeg. 3 (tiga) actor yang melakukan kegiatan diantaranya: Nasabah, Teller, dan Petugas maploeg. 2 (dua) include points, dan 3 (tiga) extend points.



Gambar 3. Sequence Diagram

Dari Gambar 3 Sequence Diagram terdapat 3 (tiga) Actor yang melakukan kegiatan, yaitu, Nasabah, Teller, Petugas Maploeg. 3 (tiga) Lifeline yang
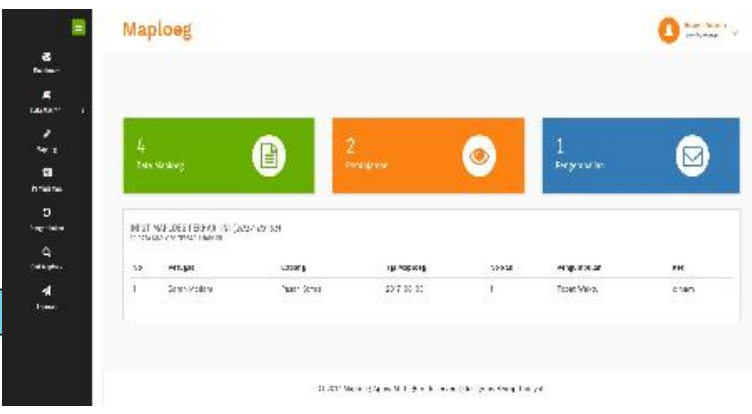

Gambar 5. Tampilan Menu Home

Ada 7 (tujuh) pilihan dalam home yaitu: Master Cabang/Petugas, Maploeg, Pinjam, Pengembalian, Cari, dan Laporan (Gambar 6).


Gambar 6. Tampilan Master Cabang

Pada tampilan Master Cabang,menginformasikan menu untuk input data cabang. Dalam menu input 
data cabang ada beberapa field yang harus diisi adalah Nama Cabang, Alamat lengkap cabang, dan nomor telepon cabang (Gambar 7).
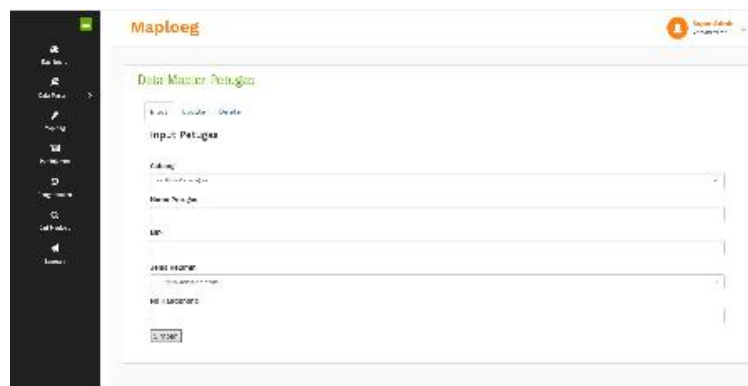

Gambar 7. Tampilan Master Petugas

Pada tampilan Master Petugas, menginformasikan menu untuk input data petugas. Dalam menu input data petugas ada beberapa field yang harus diisi adalah pilih Cabang, nama petugas, jenis kelamin dan nomorHP petugas (Gambar 8).


Gambar 8. Tampilan Maploeg

Pada tampilan Maploeg, menginformasikan menu untuk input register Maploeg. Dalam menu input data maploeg ada beberapa field yang harus diisi adalah pilih petugas, pilih Cabang, tanggal maploeg, rak dan upload file (Gambar 9).


Gambar 9. Tampilan Peminjaman

Pada tampilan Peminjaman, menginformasikan menu Histori Peminjaman Maploeg (Gambar 10).


Gambar 10. Tampilan Pengembalian

Pada tampilan Pengembalian, menginformasikan Menu Histori Pengembalian Maploeg.
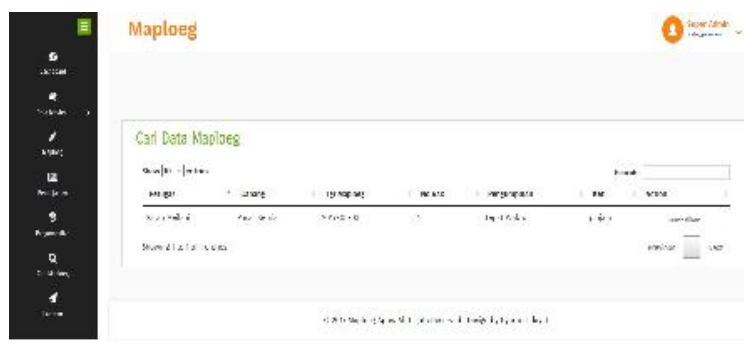

Gambar 11. Tampilan Cari Maploeg

Pada tampilan Cari Maploeg, menginformasikan Menu Histori Cari Maploeg berdasarkan Search nama petugas.
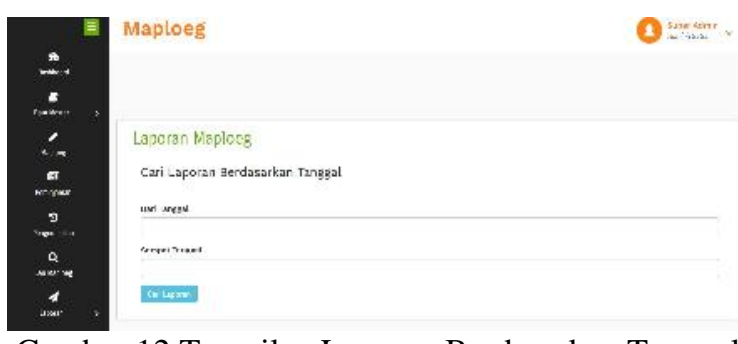

Gambar 12 Tampilan Laporan Berdasarkan Tanggal dan Bulan

Pada tampilan Laporan, menginformasikan menu Laporan administrasi Maploeg Berdasarkan Tanggal dan Bulan dan dapat di export to excel.

\section{KESIMPULAN}

Sistem administrasi register Maploeg di BTN masih konvensional yang tidak tersusun dengan rapi sehingga baik register maupun fisik rentan kehilangan arsip, akibatnya kesulitan mencari Maploeg saat dibutuhkan. Upaya mengatasi kelemahan atau kendala dari sistem ini yaitu dengan membuatkan sistem yang terkomuterisasi agar dapat mengontrol alur regiter Maploeg baik saat penginputan ataupun pencarian kembali. Sistem yang 
terkomputerisasi lebih efisien dan memudahkan pegawai saat membutuhkannya

\section{REFERENSI}

[1] Adebayo F.A. (2007). Management Information System for Managers. Ado-Ekiti: Green Line Publishers

[2] D’Atri A., De Marco M., Casalino N. (2008). Interdisciplinary Aspects of Information Systems Studies, Physica-Verlag, Germany: Springer

[3] David, Kroenke. (2015). MIS Essentials. 4eds. Boston: Pearson.

[4] Fahrudin, Alex. at al. (2011). Pembangunan Sistem Informasi Layanan Haji Berbasis Web Pada Kelompok Bimbingan Ibadah Haji Ar rohman Mabrur Kudus. Journal Speed - Sentra Penelitian Engineering dan Edukasi. 3(1).

[5]Haryadi, Hendi. (2011). Administrasi Perkantoran Untuk Manager Dan Staf.Jakarta: Visimedia

[6] Hermansyah. (2014). Hukum Perbankan Nasional Indonesia. Edisi 2.

Jakarta: Kencana

[7] Https://id.wikihow.com/Belajar-BahasaPemrograman-PHP-dan-MySQL, (diunduh 6 Maret 2018)

[8] Jayanti, Dwi \& Siska Iriani. (2014). Sistem Informasi Pengajaran pada CV Blumbang Sejati Pacitan. Journal Speed-Sentra Penelitian Enginering dan Edukasi. 6(3).

[9] Leonard, Jessup, M. \& Joseph S. Valacich. (2008). Information Systems Today. 3rd ed. Pearson Publishing.

[10] Mahdiana, Deni.( 2011). Analisa dan Rancangan Sistem Informasi Pengadaan Barang dengan Metodologi Berorientasi Objek: studi kasus PT Liga Indonesia. Journal Telematika Mkom. 3(2).

[12] Mustikowati, Dyah Ayu. (2013). Pembangunan Sistem Informasi Pendataan Rumah Tangga Miskin Kecamatan ulakan Kabupaten Pacitan. Journal Speed - Sentra Penelitian Engineering dan Edukasi.5(3)
[13] Udin, M. Silalahi. (2008). Single Presence Policy Ditinjau dari Perspektif Hukum Persaingan Usaha, Jurnal Hukum Bisnis 27(2), 31 .

[14] Whitten J. L., Bentley L.D. and Dittman K.C. (2004). System Analysis and Design Methods, $6^{\text {th }}$ eds. Mc.Graw-Hillk, New York. 